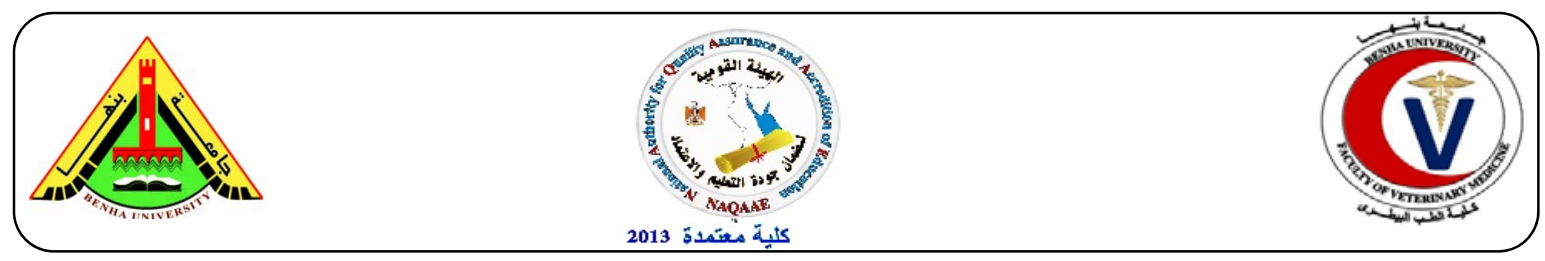

\title{
Fractionation of Amino Acids and Fatty Acids of Fresh Local and Frozen Imported Chicken Meat
}

\author{
Fatin S. Hasanin ${ }^{1}$, Omayma M.A.L. Maghraby ${ }^{2}$ and Ahmed M. Mostafa ${ }^{2}$ \\ ${ }^{1}$ Food Control Dept., Fac. Vet. Med., Benha University. ${ }^{2}$ Food Hygiene Dept., Animal Health research \\ Institute, Dokki.
}

\section{A B S T R A C T}

Sixty random samples of fresh local and frozen imported chicken meat (30 of each) were collected for fractionation of amino and fatty acids. The results showed that the fresh local chicken meat had the highest content of Histidine (3.27 \%), Isoleucine (4.81\%), Leucine $(7.63 \%)$, Lysine $(9.08 \%)$, Phenylalanine (4.32\%), Methionine (2.56\%), Threonine (3.91\%), Tryptophan $(0.35 \%)$, Glycine $(4.75 \%)$ and Valine $(4.74 \%)$. In the same time, the frozen imported chicken meat had the highest content of Alanine (5.76\%), Arginine (6.28\%), Aspartic acid (9.02\%), Glutamic acid (16.24\%), Serine (4.17\%) and Tyrosine (3.43\%). Total Mono-Unsaturated Fatty acids in the examined fresh local and frozen imported chicken meat samples were (1996 and $1749 \mathrm{mg} / 100 \mathrm{~g}$ fat), total poly-unsaturated fatty acids were $(976 \mathrm{and} 910 \mathrm{mg} / 100 \mathrm{~g}$ fat), and total saturated fatty acids were (1657 and $1892 \mathrm{mg} / 100 \mathrm{~g}$ fat), respectively. Finally, the fresh local chicken meat had a higher nutritive value and lower shelf-life than the frozen imported chicken meat.

Key words: Amino acids, fatty acids, chicken meat.

\section{INTRODUCTION}

$r_{w}$ hicken are good source of animal protein of high biologic value, which contains all the essential amino acids required for human nutrition. Amino acid composition of meat components as being a part of meat protein can play a significant role in meat identification (Saad et al. 2013). Much of the value of a protein food is based on its amino acid content whereby the high nutritional value is related to a high presence of essential amino acids (Bender, 1992). Amino acids represent over $90 \%$ of the crude protein in the body of poultry (Hunton, 1995). In a comparison to red meat, chicken meat has a high nutritional value, low cholesterol and saturated fatty acids level which are the main reasons for arteriosclerosis, and heart diseases due to the deposition on the blood vessels (FAO,
1992). Amino acid and fatty acid composition have been known to have an effect on chicken meat taste and flavor that can be influenced by genotypes, rearing systems and feeds (Wattanachant, 2008). The amino acid profile is an important parameter because some amino acids cannot be synthesized by human and must be obtained from diet (Alina and Ovidiu, 2007). Amongst the fatty acids profile of meats, the high levels of unsaturated fatty acids are usually associated to poultry. Unsaturated fatty acids are regarded as beneficial to human health (Babji et al. 1980). Individual cuts of poultry meat differ in contents of fat. 'Marbling' typical of meat of large farm animals does not occur in poultry meat. An important feature of poultry meat from dietetic aspects is an increased content of fatty acids, particularly 
linoleic acid, linolenic acid and arachidonic acid (Matušovičová, 1986). Arachnoic acid and Docosahexaenoic acid (DHA) are the only essential fatty acids. Arachinoic acid is necessary for growth, proper hydration and healthy hair. While, DHA is necessary for learning, intelligence and visual activity. Alterations in brain 22:6n-3 and other long chain fatty acids have been associated with changes in physiological function for example enzyme activity (Masterjohn, 2005).

Therefore, the aim of the present study was to compare the nutritional value of fresh local and frozen imported chicken meat, through their content of amino acids and fatty acids.

\section{MATERIALS AND METHODS}

\subsection{Collection of samples:}

Sixty random samples of fresh local and frozen imported chicken meat (30 of each) were collected from different shops, supermarkets and hypermarkets in different localities in Kalyobia governorate. All samples were kept in an ice box during transportation to the laboratory with minimum time of delay. Then, all breasts and thighs were separately dissected from each carcass, chopped together and analyzed as rapidly as possible for fractionation of amino and fatty acids.

\subsection{Fractionation of amino acids:}

The technique recommended by Mabbott (1990) for fractionation of amino acids was applied by Gas Liquid Chromatography (GLC).

\subsection{Fractionation of fatty acids:}

\subsubsection{Extraction of fat from chicken meat:}

One hundred grams of the sample were placed in a $500 \mathrm{ml}$ closed stopper flask then, $300 \mathrm{ml}$ of n-hexane was added, and the flask was shacked for $30 \mathrm{~min}$. using horizontal shaker and left for 24 hours at room temperature. The homogenated mixture was filtered and the residue was re-extracted as mentioned above. The combined filtrates were evaporated under reduced pressure according to AOAC (2000).

\subsubsection{Identification and determination of fatty acids:}

Fatty acids were determined in chicken meat by Gas Chromatography technique (GC) according to Aura et al. (1995).

\subsubsection{Isolation and extraction of fatty acids:}

The fats under study were saponified with ethanolic potassium hydroxide $(40 \%, \mathrm{w} / \mathrm{v})$ for 24 hours at room temperature according to the method of AOCS (1993). The aqueous layer (containing potassium salt of fatty acids and free from unsaponifiable matter) was acidified with HCL $(0.5 \mathrm{~N})$, then it was extracted three times with petroleum ether. The petroleum ether extract was washed several times with distilled water, and dried over anhydrous sodium sulphate.

\subsubsection{Methylation of fatty acids:}

The obtained fatty acids were converted to methyl esters as follows:

The extracted fatty acids were dissolved in anhydrous diethyl ether $(0.5-1.0 \mathrm{ml})$ and methylated by drop wise addition of diazomethane solution (Vogel, 1975) until the yellow color persisted. The mixture was then left at room temperature for 15 minutes and the solvent was evaporated on a water bath maintained at $60^{\circ} \mathrm{C}$. Finally, the methyl ester of fatty acids was dissolved in chloroform and aliquots of this solution were subjected to analysis by GC.

\subsubsection{Separation of fatty acid methyl esters:}

The fatty acids methyl esters were analyzed by Hewlett Packard gas chromatography (5890 series) equipped with flame ionization detector. The chromatograph was fitted with FFAP $(2.5 \mathrm{~m} \times 0.30 \mu \mathrm{m}$ film thickness and $0.32 \mathrm{~mm}$ diameter). Capillary column coated with polyethylene glycol. The column oven temperature was programmed from $50^{\circ} \mathrm{C}$ to $240^{\circ} \mathrm{C}\left(7^{\circ} \mathrm{C}\right.$ /min.) and finally kept at $240^{\circ} \mathrm{C}$ for 30 minutes. Injector and detector temperature 
were $250^{\circ} \mathrm{C}$ and $260^{\circ} \mathrm{C}$, respectively. Gases flow rates were 33,30 and $330 \mathrm{ml} / \mathrm{min}$. for $\mathrm{N} 2, \mathrm{H} 2$ and air, respectively. The flow rate inside column was $2 \mathrm{ml} / \mathrm{min}$. Under these conditions, all peaks from $\mathrm{C} 8$ to $\mathrm{C} 22$ homologous series well defined. Peak identification was performed by comparison of the relative retention time (RTT) for each peak with those of standard chromatograms. The peak was measured by triangulation and the relative proportions of the individual compound were therefore obtained by determination of the partial areas in relation to the total area.

\section{RESULTS}

Results presented in table (1) revealed that the fractionation of amino acids of fresh local chicken meat were Histidine (3.27\%), Isoleucine $(4.81 \%)$, Leucine $(7.63 \%)$, Lysine (9.08\%), Phenylalanine (4.32\%), Methionine (2.56\%), Threonine (3.91\%), Tryptophan $(0.35 \%)$, Glycine $(4.75 \%)$, Valine (4.74\%), Alanine (5.60\%), Arginine (6.12\%), Aspartic acid (8.97\%), Glutamic acid $(15.88 \%)$, Serine $(4.03 \%)$ and Tyrosine $(3.29 \%)$. In the same time, the fractionation of amino acids of frozen imported chicken meat were Alanine (5.76\%), Arginine (6.28\%), Aspartic acid (9.02\%), Glutamic acid (16.24\%), Serine (4.17\%), Tyrosine (3.43\%), Histidine $(2.99 \%)$, Isoleucine $(4.45 \%)$, Leucine $(7.12 \%)$, Lysine $(8.86 \%)$, Phenylalanine (4.07\%), Methionine (2.30\%), Threonine (3.64\%), Tryptophan $(0.29 \%)$, Glycine $(4.69 \%)$ and Valine (4.59\%). Table (2) revealed that the fractionation of fatty acids of the fresh local chicken meat were Palmitoleic (352 mg/100 g fat), Oleic (1644 $\mathrm{mg} / 100 \mathrm{~g}$ fat), Total Mono-Unsaturated Fatty acids (1996 mg/100 g fat), Linoleic (639 mg/100 g fat),Linolenic (106 mg/100 $\mathrm{g}$ fat $)$, Eicosadienoic acid $(21 \mathrm{mg} / 100 \mathrm{~g}$ fat),Dihomo- $\gamma$-linolenic $(30 \mathrm{mg} / 100 \mathrm{~g}$ fat $)$, Arachidonic $(126 \mathrm{mg} / 100 \mathrm{~g}$ fat $)$, Eicosapentaenoic "EPA" (11 mg/100 g fat),Docosapentaenoic "DPA" ( $25 \mathrm{mg} / 100$ $\mathrm{g}$ fat),Docosahexaenoic "DHA" (18 mg/100 $\mathrm{g}$ fat), Total Poly-Unsaturated Fatty acids (976 mg/100 g fat), Lauric acid (36 mg/100 $\mathrm{g}$ fat), Myristic (54 mg/100 g fat), Palmitic (1158 mg/100 g fat), Stearic (409 mg/100 g fat) and Total Saturated Fatty acids (1657 $\mathrm{mg} / 100 \mathrm{~g}$ fat).

Table (1): Fractionation of amino acid composition (g/100 g protein) in the examined samples of fresh local and frozen imported chicken meat $(n=30)$.

\begin{tabular}{lcc}
\hline Amino acids & Fresh local chicken meat & Frozen imported chicken meat \\
\hline Essential Amino Acids: & 3.27 & \\
Histidine & 4.81 & 2.99 \\
Isoleucine & 7.63 & 4.45 \\
Leucine & 9.08 & 7.12 \\
Lysine & 4.32 & 8.86 \\
Phenylalanine & 2.56 & 4.07 \\
Methionine & 3.91 & 2.30 \\
Threonine & 0.35 & 3.64 \\
Tryptophan & 4.74 & 0.29 \\
Valine & & 4.59 \\
Non Essential Amino Acids: & 5.60 & \\
Alanine & 6.12 & 5.76 \\
Arginine & 8.97 & 6.28 \\
Aspartic acid & 4.75 & 9.02 \\
Glycine & 15.88 & 4.69 \\
Glutamic acid & 4.03 & 16.24 \\
Serine & 3.29 & 4.17 \\
Tyrosine & & 3.43 \\
\hline
\end{tabular}


Table (2): Fractionation of fatty acids (FAs) composition (mg/100 g fat) in the examined samples of fresh local and frozen imported chicken meat $(n=30)$.

\begin{tabular}{lcc}
\hline Fatty acids & Fresh local chicken meat & Frozen imported chicken meat \\
\hline Lauric acid (C12:0) & 36 & 42 \\
Myristic (C14:0) & 54 & 66 \\
Palmitic (C16:0) & 1158 & 1270 \\
Stearic (C18:0) & 409 & 514 \\
Total Saturated F.As & 1657 & 1892 \\
Palmitoleic (C16:1) & 352 & 331 \\
Oleic (C18:1) & 1644 & 1418 \\
Total Mono-Unsaturated F.As & 1996 & 1749 \\
Linoleic (C18:2) & 639 & 622 \\
Linolenic (C18:3) & 106 & 93 \\
Eicosadienoic acid (C20:2) & 21 & 16 \\
Dihomo- $\gamma$-linolenic (C20:3) & 30 & 23 \\
Arachidonic (C20:4) & 126 & 112 \\
Eicosapentaenoic "EPA" (C20:5) & 11 & 10 \\
Docosapentaenoic "DPA" (C22:5) & 25 & 21 \\
Docosahexaenoic "DHA" (C22:6) & 18 & 13 \\
Total Poly-Unsaturated F.As & 976 & 910 \\
\hline
\end{tabular}

In the same time, the fractionation of fatty acids of frozen imported chicken meat were Lauric acid (42 mg/100 g fat), Myristic (66 $\mathrm{mg} / 100 \mathrm{~g}$ fat), Palmitic (1270 mg/100 g fat), Stearic $(514 \mathrm{mg} / 100 \mathrm{~g}$ fat), Total saturated fatty acids (1892 mg/100 g fat), Palmitoleic (331 mg/100 g fat), Oleic (1418 mg/100 g fat), Total Mono-Unsaturated Fatty acids (1749 mg/100 g fat), Linoleic (622 mg/100 $\mathrm{g}$ fat), Linolenic (93 mg/100 $\mathrm{g}$ fat), Eicosadienoic acid $(16 \mathrm{mg} / 100 \mathrm{~g}$ fat $)$, Dihomo- $\gamma$-linolenic (23 mg/100 $\mathrm{g}$ fat), Arachidonic (112 mg/100 g fat), Eicosapentaenoic "EPA" (10 mg/100 g fat), Docosapentaenoic "DPA" (21 mg/100 g fat), Docosahexaenoic "DHA" (13 mg/100 $\mathrm{g}$ fat) and Total Poly-Unsaturated Fatty acids $(910 \mathrm{mg} / 100 \mathrm{~g}$ fat $)$.

\section{DISSCUSION}

It is evident from the results recorded in table (1) that the fractionation of amino acid in the examined samples were nearly similar to those obtained by Paul and Southgate (1978) who indicated that the amino acids content (g/ $100 \mathrm{~g}$ protein) of the chicken meat was Lysine (8.96), Threonine(4.16), Valine (4.80), Methionine (2.40), Isoleucine (4.64), Leucine (7.52), Phenylalanine (4.48), Histidine (3.04), Arginine (6.24), Aspartic acid (9.12), Serine (4.00), Glutamic acid (16.48), Glycine (4.82), Tyrosine(3.52) and Alanine (5.76). Lower results were obtained by Mavromichalis et al. (2000) who recorded that the amino acids composition of chicken meat (g/100 g protein) were Leucine (6.14), Lysine (6.23), Tyrosine (1.95), Valine (3.75), Arginine (4.98), Alanine (4.34), Aspartic acid (6.80), Glutamic acid (11.25), Glycine (3.13), and Serine (2.92). Results presented in table (1) revealed that the examined samples of fresh local chicken meat had the highest content of Histidine, Isoleucine, Leucine, Lysine, Phenylalanine, Methionine, Threonine, Tryptophan, Glycine, and Valine, and had the lowest content of Alanine, Arginine, Aspartic acid, Glutamic acid, Serine, and Tyrosine than the examined samples of frozen imported chicken meat. According to the above mentioned results, the fresh local chicken samples had the highest content of essential 
amino acids and lowest content of nonessential amino acids than frozen imported chicken samples. So, the fresh local chicken samples had higher percent nutritive value than frozen imported chicken samples.

Nine of the amino acids present in proteins are essential (or semi-essential) because the human body cannot synthesize them from other compounds, and therefore must take them up from food. Therefore, the requirement for dietary protein consists of two components; (a) a requirement for the nutritionally essential amino acids, and (b) the need to meet the requirement for nonspecific nitrogen in order to supply the nitrogen necessary for synthesis of the nutritionally not essential amino acids and other physiologically important nitrogen containing compounds (nucleic acids, creatine, porphyrins) (Pellett and Young, 1990). The results of total saturated fatty acid, total monounsaturated fatty acid and total polyunsaturated fatty acid obtained in table (2) were lower than those recorded by Suriani et al. (2014). Table (2) revealed that the examined samples of fresh local chicken meat had the highest content of Palmitoleic, Oleic, Total Mono-Unsaturated Fatty acids, Linoleic, Linolenic, Eicosadienoic acid, Dihomo- $\gamma$-linolenic, Arachidonic, Eicosapentaenoic "EPA", Docosapentaenoic "DPA", Docosahexaenoic "DHA" and total poly-unsaturated fatty acids and had the lowest content of Lauric acid, Myristic, Palmitic, Stearic and total saturated fatty acids than the frozen imported chicken meat. According to the above mentioned result, the fresh local chicken samples had the highest content of Total PolyUnsaturated Fatty acids and Total MonoUnsaturated Fatty acids and lowest content of Total Saturated Fatty acids than frozen imported chicken samples. This means that the fresh local chicken samples had higher nutritive value than frozen imported chicken samples.

\section{REFERENCES}

Alina, H., Ovidiu, T. 2007. Determination of total protein in some meat products. Analele Stiintifice ale Universitatii, Alexandru Ioan Cuza, Sectiunea Geneticasi Biologie Moleculara, TOM VIII.

American Oil Chemists Society "AOCS" 1993. Official Methods and Recommendation Practices of the American Oil Chemists Society. $4^{\text {th }}$ Ed. Published by American Oil Chemists Society, 1608, Broad Moor drive, Champaign, USA.

Association of Official Analytical Chemists "AOAC" 2000. Official Methods of Analysis. $13^{\text {th }}$ Ed., Horwitz. w; D. (Editor), Academic Press, Washington D.C, USA.

Aura, A., Forssell, P., Mustranta, A., Poutanen, K. 1995. Transesterification of soy lecithin by lipase and phospo-lipase. J. Amer. Oil Chem. Soc., 72(11):1375-1379.

Babji, A.S., Froning, G.W., Saterlle, L.D. 1980. Protein nutritional quality of mechanically deboned poultry meat as predict by de C-PER assay. Journal of Food Science., 45(3): 441-443.

Bender, A. 1992. Meat and Meat Products in Human Nutrition in Developing Countries. Food and Agriculture Organization of the United Nations, Rome, 91p.

FAO" Food and Agriculture Organization of United Nation" 1992. Manual of Food Quality Control. Microbiological analysis. BiB Tex.

Hunton, P. 1995. Poultry Product. Elsevier Science, B.V. Amsterdam, 600p.

Mabbott, A.G. 1990. Qualitative amino acid analysis of small peptide by GC. J. Chemical Education, 67(5):441-445.

Masterjohn, C. 2005. My Experience with Vegetarianism. Retrieved from: http://www.cholesterol-andhealth.com/Vegetarianism-OldVersion.html (Assessed date: 22 November, 2015). 
Matušovičová, E. 1986. Technology of Poultry Production (in Slovak). Príroda, Bratislava. pp. 393

Mavromichalis, I., Emmert, J., Aoyagi, S., Baker, D. 2000. Chemical Composition of Whole Body, Tissues, and Organs of Young Chickens (Gallus domesticus). Journal of food composition and analysis, 13:799-807.

Paul, A.A., Southgate, D.A.T. 1978. McCance and Widdowson's. The Composition of Foods, 4th (revised and extended) Edn. of MRC Special Report No. 297. Elsevier/ NorthHolland Biomedical Press, Amsterdam.

Pellett, P.L., Young, V.R. 1990. Role of meat as a source of protein and essential amino acids in human protein nutrition. In A.M. Pearson, \& T.R. Dutson, Advances in meat research 6, 329-370. New York: Elsevier Applied Science.

Saad, M.S., Ibraheem, H.M., Hassan, M.A., Hassan, F.Y. 2013. Fractionation of amino acids and fatty acids of frozen poultry meat. Benha Veterinary Medical Journal, 24(1):86-91

Suriani, N.W., Purnomo, H., Estiasih, T., Suwetja, I.K. 2014. Physicochemical Properties, Fatty Acids Profile and Cholesterol Content of Indigenous Manado Chicken, Broiler and Spent Hen Meat. Int. J. Chem Tech Res., 6 (7):3896-3902.

Vogel, S.F. 1975. Fatty acid composition of raw and processed meats. Food Technol. 29: 147-152.

Wattanachant, S. 2008. Factors affecting the quality characteristics of Thai indigenous chicken meat. Suranaree J. Sci. Technol. 15(4):317-322. 